\title{
Nonlinear Control for Bioprocesses with Model Uncertainties and External Disturbances
}

\author{
Cecilia Fernández $\mathbb{D}^{\mathbb{D}}$, Nadia Pantano $\mathbb{i}$, Leandro Rodriguez $\mathbb{D}$, and Gustavo Scaglia
}

Instituto de Ingeniería Química, Universidad Nacional de San Juan (UNSJ), CONICET, Avenida Libertador General San Martin Oeste 1109, San Juan J5400ARL, Argentina

Correspondence should be addressed to Cecilia Fernández; mcfernandez@unsj.edu.ar

Received 21 February 2020; Revised 26 April 2021; Accepted 7 May 2021; Published 18 May 2021

Academic Editor: Shangce Gao

Copyright (c) 2021 Cecilia Fernández et al. This is an open access article distributed under the Creative Commons Attribution License, which permits unrestricted use, distribution, and reproduction in any medium, provided the original work is properly cited.

\begin{abstract}
In this paper, a new alternative for profiles tracking control considering additive uncertainties is proposed. Based on a previously presented work about a nonlinear and multivariable controller design for a fed-batch bioethanol production, parametric uncertainty and process disturbance are taken into account to find a more reliable control strategy for a successful industrial implementation. To decrease the uncertainties effect, an approach based on the error estimation using Newton's backward interpolation is included in the design equations. The proposed modification assures the error convergence to zero (demonstration is shown) despite the uncertainties, which is one of the main contributions of this work. A comparison between the new, the original proposal, and another methodology is exposed.
\end{abstract}

\section{Introduction}

Biological processes are becoming more frequent nowadays due to the wide variety of products obtained from them [1] and their possibility of making some processes environmentally friendly while high standard products are obtained $[2,3]$. The fed-batch operation mode is which most interest awake for its main benefits $[4,5]$. One of the most interesting advantages is the substrate concentration regulation in the cultivation medium by a suitable feed rate profile [6], obtaining better production yields and minimizing the production costs [5, 7]. However, bioprocesses control is required to follow a certain feed flow rate and get stability and the best productivity [8]. Furthermore, the mathematical representation of the process is the key to achieve good results.

A mathematical model provides a map from inputs to responses. The quality of a model depends on how closely its responses match those of the true plant. However, a model set that includes the true physical plant can never be constructed [9]. Generally, a bioprocess modeling presents particular difficulty in their parameters determination caused by the poorly understood microorganism's dynamics (multivariable and highly nonlinear dynamics), the strongly coupled variables, and the presence of numerous external disturbances, which leads to having many modeling uncertainties [10]. Furthermore, sometimes those parameters are determined without a previous model analysis, or their values are not informed with their respective confidence intervals $[11,12]$. Moreover, time-varying parameters are usually assumed as constants [13]. Also, the uncertainties related to the processing technologies parameters are rarely considered [14]. The dismissal of all these aspects leads to a poor real-life representation and, consequently, to a bad performance with severe risks $[15,16]$. Therefore, the main task to guarantee the bioprocess quality implies finding a way to control these distortions [17-19]. For this reason, the development of new control schemes that reduce the effect of uncertainties in the tracking error has become an attention focus for the scientific community $[11,15]$.

One of the problems to take into account is the feasibility of the occurrence of events in systems with uncertainty, for this, the uncertainty theory was introduced [20]. On the other hand, a very interesting way to describe uncertainty is 
using the uncertain fractional differential equation (UFDE), which allows keeping a record of some properties to be considered a posteriori, which is fundamental in the evolution of uncertainties [21, 22]. Furthermore, the contemplation of uncertainties is approached with different strategies, depending on the nature of the system under study [22-24]. One of the most used strategies for model parameter identification and/or estimation involves an offline optimization using a nominal model of the process [25-30]; the main disadvantage of this methodology is that the variability of microorganisms decreases the possibility of batch-to-batch repeatability. To improve the results of nominal optimization, a methodology called "run to run" optimization appears, which uses previous runs information to optimize the operation of subsequent ones [31-37]. Another strategy is the online optimization of the model parameters [38-45]. This kind of optimization is difficult to perform since the available models might only be locally valid and thus inappropriate for predicting final concentrations [46].

On the other hand, many scientists have developed some feedback control strategies to deal with bioprocess uncertainties. Optimal control, nonlinear model predictive control, hybrid control, adaptive control, fuzzy control, tracking control, and neural network are examples of them [47, 48]. But, due to the online implementation difficulty, the high computational cost, the imprecise mathematical models, and online solutions, their use for bioprocesses is limited [7] and is still a research topic [49].

For the specific case of ethanol production defined by Hunag et al. [36], Fernández et al. [50] presented a controller design focused on looking for control actions, to track predefined concentration profiles. As the controller structure comes from the mathematical model of the process, it can be implemented in many systems. The procedure is characterized by its simplicity, versatility, and precision. Besides, only basic knowledge of numerical methods and linear algebra is needed to implement it. One of the main contributions of that work was to achieve the tracking error convergence to zero. Also, the technique was tested against different disturbances and compared with a typical PID controller.

This manuscript aims to improve the control strategy presented in [50]. In this sense, predefined trajectories can be tracked while estimating the difference between the model and the real plant in each sampling time (error estimation). To reach this objective, another term is incorporated into the controller structure, which symbolizes model uncertainties and outside instabilities that are evaded with Newton's backward interpolation. Moreover, the higher the interpolation order, the better the estimation and the smaller the tracking error. Besides, this change guarantees uniformity in the signal and progressive reduction of tracking error, achieving improvements of up to $98 \%$ in some cases.
In [51], the problem of optimal profiles tracking control under uncertainties for a fed-batch bioprocess with two control actions is addressed with excellent results. In that manuscript, the authors add tracking error integrators in the control action calculation to reduce the additive uncertainties effect. However, the strategy presented in this paper has the advantage that adding the additive uncertainty term does not increase the order of the system, making mathematical development even simpler. Moreover, the ethanol bioprocess is an underactuated system with only one control action, so the control challenge is even greater than in [51]. Thus, a solution to the real trouble of multivariable and nonlinear tracking control in the presence of additive uncertainties is proposed, without increasing the system order.

The manuscript is presented as follows: first, a summary of the process under study and the original control technique is described to contextualize the problem. Second, the contribution of this work is detailed, including the relevant demonstrations. Third, algorithms are tested and compared. Lastly, conclusions are shown.

\section{Process and Control Description}

2.1. Mathematical Model of the Process. Hunag et al. [36] proposed a mathematical model for a fed-batch ethanol production, using Saccharomyces diastaticus yeast to carry out the fermentation. The temperature was fixed at $35.8^{\circ} \mathrm{C}$, airflow at $1.5 \mathrm{vvm}$, and $\mathrm{pH}$ at 5.0. The only system input is the feed rate $(U)$, which is a $50 \%$ glucose and $50 \%$ fructose combination. The state variables are biomass $(X)$, ethanol $\left(P_{1}\right)$, glycerol $\left(P_{2}\right)$, glucose $\left(S_{1}\right)$, and fructose $\left(S_{2}\right)$ concentration inside the bioreactor:

$$
\left\{\begin{array}{l}
\dot{X}(t)=\left(\mu_{1}+\mu_{2}\right) X-\frac{U}{V} X, \\
\dot{S}_{1}(t)=-\left(\frac{q\left(S_{1} / P_{1}\right)}{Y_{\left(P_{1} / S_{1}\right)}}+\frac{q_{\left(S_{1} / P_{2}\right)}}{Y_{\left(P_{2} / S_{1}\right)}}\right) X+\frac{U}{V}\left(\lambda S_{f}-S_{1}\right), \\
\dot{S}_{2}(t)=-\left(\frac{q_{\left(S_{2} / P_{1}\right)}}{Y_{\left(P_{1} / S_{2}\right)}}+\frac{q_{\left(S_{2} / P_{2}\right)}}{Y_{\left(P_{2} / S_{2}\right)}}\right) X+\frac{U}{V}\left((1-\lambda) S_{f}-S_{2}\right), \\
\dot{P}_{1}(t)=\left(q_{\left(S_{1} / P_{1}\right)}+q_{\left(S_{2} / P_{1}\right)}\right) X-\frac{U}{V} P_{1}, \\
\dot{P}_{2}(t)=\left(q\left(S_{1} / P_{2}\right)+q\left(S_{2} / P_{2}\right)\right) X-\frac{U}{V} P_{2},
\end{array}\right.
$$

where 


$$
\begin{aligned}
\dot{V}(t) & =U, \\
q_{\left(S_{1} / P_{1}\right)} & =\frac{v_{S_{1} P_{1}} S_{1}}{K_{S_{1} P_{1}}+S_{1}} \frac{k_{S_{1} P_{1}}}{k_{S_{1} P_{1}}+P_{1}}, \\
\mu_{1} & =\frac{\mu_{m_{1}} S_{1}}{\left(K_{S_{1}}+S_{1}+S_{1}^{2} / K_{S_{1 I}}\right)} \frac{K_{P_{1}}}{\left(K_{P_{1}}+P_{1}+P_{1}^{2} / K_{P_{1 I}}\right)}, \\
q_{\left(S_{1} / P_{2}\right)} & =\frac{v_{S_{2} P_{2}} S_{2}}{K_{S_{2} P_{2}}+S_{2}} \frac{k_{S_{2} P_{2}}}{k_{S_{2} P_{2}}+P_{2}}, \\
\mu_{2} & =\frac{\mu_{m_{2}} S_{2}}{\left(K_{S_{2}}+S_{2}+S_{2}^{2} / K_{S_{2 I}}\right)} \frac{K_{P_{2}}}{\left(K_{P_{2}}+P_{1}+P_{1}^{2} / K_{P_{2 I}}\right)}, \\
q_{\left(S_{1} / P_{2}\right)} & =\frac{v_{S_{1} P_{2}} S_{1}}{K_{S_{1} P_{2}}+S_{1}} \frac{k_{S_{1} P_{2}}}{k_{S_{1} P_{2}}+P_{2}}, \\
q_{\left(S_{2} / P_{1}\right)} & =\frac{v_{S_{2} P_{1}} S_{2}}{K_{S_{2} P_{1}}+S_{2}} \frac{k_{S_{2} P_{1}}}{k_{S_{2} P_{1}}+P_{1}} .
\end{aligned}
$$

$V$ is the volume of culture medium; $\mu_{1}$ and $\mu_{2}$ are the specific yeast growth rate, $q_{S 1 / P 1}$ and $q_{S 2 / P 1}$ are the specific ethanol production rate, and $q_{S 1 / P 2}$ and $q_{S 2 / P 2}$ are the specific glycerol production rate, in all cases from glucose and fructose, respectively. $U$ is the control action. Initial conditions for ethanol fermentation are shown in Table 1, while the nomenclature, description, and values of parameters are in Table 2.

2.2. Controller Structure Design. In [50], a technique that finds $U$ to make the system track predefined profiles (references) is proposed. For this methodology, design is supposed that both the references and the states are known at each sampling instant. This last assertion is far from reality, so system states were estimated with neural network state estimators previously designed and published [52]. In Figure 1, reference concentration profiles and $U$ are shown. The following is a brief description of the technique described in [50]:
Firstly, the system equation (1) is integrated using numerical methods. Euler is used for its simplicity:

$$
\left(\frac{\mathrm{d} \sigma}{\mathrm{d} t}\right)=\frac{\sigma_{n+1}-\sigma_{n}}{T_{S}} .
$$

In (3), $\sigma$ symbolizes states variables, $\sigma_{n}$ is the current value of $\sigma$ measured online, and $\sigma_{n+1}$ is the $\sigma$ value in the next measurement instant. $T_{S}$ is the sampling time $(0.1 \mathrm{~h})$ [53]. The process total time is $15.7 \mathrm{~h}\left(T_{f}\right)$.

Then, $\sigma_{n+1}$ are approached with

$$
\begin{aligned}
\underbrace{\sigma_{r e f, n+1}-\sigma_{n+1}}_{\text {error }_{n+1}} & =k_{\sigma} \underbrace{\left(\sigma_{r e f, n}-\sigma_{n}\right)}_{\text {error }_{n}} \longrightarrow \sigma_{n+1} \\
& =\sigma_{r e f, n+1}-k_{\sigma}\left(\sigma_{r e f, n}-\sigma_{n}\right),
\end{aligned}
$$

where $\sigma_{\text {ref }}$ are the reference state variables and $k_{\sigma}$ is the controller parameter for the variable $\sigma$. For this process, the controller parameters are $k_{X}, k_{P 1}, k_{P 2}, k_{S 1}$, and $k_{S 2}$. Then, substituting (4) in (3),

$$
\left(\frac{\mathrm{d} \sigma}{\mathrm{d} t}\right)=\frac{\overbrace{\left[\sigma_{r e f, n+1}-k_{\sigma}\left(\sigma_{r e f, n}-\sigma_{n}\right)\right]}^{\sigma_{n+1}}-\sigma_{n}}{T_{S}}=\Delta \sigma_{n} .
$$

Replacing (5) in (1),

$$
\left\{\begin{array}{l}
\Delta X_{n}=\left(\mu_{1}+\mu_{2}\right) X_{n}-\frac{U_{n}}{V_{n}} X_{n}, \\
\Delta S_{1, n}=-\left(\frac{q\left(S_{1} / P_{1}\right)}{Y_{\left(P_{1} / S_{1}\right)}}+\frac{q\left(S_{1} / P_{2}\right)}{Y_{\left(P_{2} / S_{1}\right)}}\right) X_{n}+\frac{U_{n}}{V_{n}}\left(\lambda S_{f}-S_{1, n}\right), \\
\Delta S_{2, n}=-\left(\frac{q\left(S_{2} / P_{1}\right)}{Y_{\left(P_{1} / S_{2}\right)}}+\frac{q\left(S_{2} / P_{2}\right)}{Y_{\left(P_{2} / S_{2}\right)}}\right) X_{n}+\frac{U_{n}}{V_{n}}\left((1-\lambda) S_{f}-S_{2, n}\right), \\
\Delta P_{1, n}=\left(q\left(S_{1} / P_{1}\right)+q\left(S_{2} / P_{1}\right)\right) X_{n}-\frac{U_{n}}{V_{n}} P_{1, n}, \\
\Delta P_{2, n}=\left(q\left(S_{1} / P_{2}\right)+q\left(S_{2} / P_{2}\right)\right) X_{n}-\frac{U_{n}}{V_{n}} P_{2, n} .
\end{array}\right.
$$


Stating (6) as a matrix,

System equation (7) must have an exact solution to find $U_{n}$. Consequently, $\mathbf{b}_{\mathbf{n}}$ have to be a linear combination of $\mathbf{A}_{\mathbf{n}}$ [54]; that is to say, $\mathbf{A}_{\mathbf{n}}$ and $\mathbf{b}_{\mathbf{n}}$ must be parallel and with the same sense. One way to accomplish this is

$$
\cos \left(A_{n}, b_{n}\right)=\frac{\left\langle A_{n}, b_{n}\right\rangle}{\|A\|_{n} *\left\|b_{n}\right\|}=1 .
$$

In (8), the operation between $<>$ and $\|$.$\| represent the$ inner product and the vectors norm in $R^{n}$ space, respectively. The angle between $\mathbf{A}$ and $\mathbf{b}$ is $\theta=0^{\circ}$; this implies a positive $U_{n}$ value. If $\theta=180^{\circ}, U_{n}$ would be negative, which does not make physical sense because $U_{n}$ is a flow.

As stated in the Introduction, bioprocess systems generally involve several control objectives that may be conflicting, to balance these objectives during the design of the presented controller, the selection of a "sacrificed variable" is required. It is denoted as $S_{1 e z}$, which guarantees that (7) has an exact solution and that the references are followed. For more details on its selection and calculation, see [50]. Finally, $U_{n}$ is obtained using least squares [54]:

$$
\begin{aligned}
& \Delta X_{n}-\left(\mu_{1}+\mu_{2}\right) X_{n} \\
& \Delta S_{1, n}+\left(\frac{q\left(S_{1} / P_{1}\right)}{Y_{\left(P_{1} / S_{1}\right)}}+\frac{q\left(S_{1} / P_{2}\right)}{Y_{\left(P_{2} / S_{1}\right)}}\right) X_{n} \\
& \begin{array}{c}
\Delta S_{2, n}+\left(\frac{q\left(S_{2} / P_{1}\right)}{Y_{\left(P_{1} / S_{2}\right)}}+\frac{q_{\left(S_{2} / P_{2}\right)}}{Y_{\left(P_{2} / S_{2}\right)}}\right) X_{n} \\
\Delta P_{1, n}-\left(q_{\left(S_{1} / P_{1}\right)}+q_{\left(S_{2} / P_{1}\right)}\right) X_{n}
\end{array} \\
& \underbrace{\left[\Delta P_{2, n}-\left(q_{\left(S_{1} / P_{2}\right)}+q_{\left(S_{2} / P_{2}\right)}\right) X_{n}\right]}_{b_{n}} \\
& U_{n}=\left(A_{n}^{T} A_{n}\right)^{-1} A_{n}^{T} b_{n} .
\end{aligned}
$$

2.3. Controller Tuning. In [50], the Monte Carlo algorithm was used to find the controller parameters that make the accumulated error minimum. It consists of simulating the bioprocess $N$ times with random $k_{\sigma}$ [55]:

$$
N \geq\left[\frac{\log (1 / \delta)}{\log (1 / 1-\varepsilon)}\right] .
$$

In (10), $\delta$ is the confidence and $\varepsilon$ is the accuracy.

However, many other strategies can be used to tune this controller. In [56], a genetic algorithm and a hybrid one are proposed.

Next, the "tracking error $\left(\left\|e_{n}\right\|\right)$ " and "total error $\left(E_{p}\right)$ " concepts are introduced:

$$
\begin{aligned}
\left\|e_{n}\right\| & =\sqrt{\left(\frac{\left(X_{r e f, n}-X_{n}\right)}{\max X_{r e f, n}}\right)^{2}+\left(\frac{\left(P_{1 r e f, n}-P_{1, n}\right)}{\max P_{1 r e f, n}}\right)^{2}+\left(\frac{\left(P_{2 r e f, n}-P_{2, n}\right)}{\max P_{2 r e f, n}}\right)^{2}+\left(\frac{\left(S_{2 r e f, n}-S_{2, n}\right)}{\max S_{2 r e f, n}}\right)^{2}}, \\
E_{p, 1} & =T_{s} \sum_{n=1}^{J}\left\|e_{n}\right\|, \\
E_{p, 2} & =T_{s}\left(\sum_{n=1}^{J}\left\|e_{n}\right\| n T_{s}\right),
\end{aligned}
$$


TABLE 1: Initial conditions for ethanol fermentation.

\begin{tabular}{lc}
\hline Variable & Initial value \\
\hline$X(\mathrm{~g} / \mathrm{L})$ & 1.5 \\
$P_{1}(\mathrm{~g} / \mathrm{L})$ & 5.3 \\
$P_{2}(\mathrm{~g} / \mathrm{L})$ & 0.0001 \\
$S_{1}(\mathrm{~g} / \mathrm{L})$ & 8.6 \\
$S_{2}(\mathrm{~g} / \mathrm{L})$ & 8.6 \\
$V(\mathrm{~L})$ & 1.35 \\
\hline
\end{tabular}

where $p$ represents the simulation in progress, $p=1,2, \ldots, N$; subscripts 1 and 2 differentiate between one index and another; $n$ is the sample instant, $n=1,2, \ldots, J ; T_{f}=J T_{S}$.

In $k_{\sigma}$ selection, (12) is the function cost to be minimized.

Theorem 1. If the discrete system is given by equation (1), the control action is calculated with equation (9), and $k_{\sigma}$ take values between zero and one $\left(0<k_{\sigma}<1\right)$; then, the tracking error convergence to zero when $n$ tends to infinity is achieved.

Demonstration [50]:

Substituting the sacrificed variable in (7) and expressing the matrix system generically,

$$
\underbrace{\left[\begin{array}{l}
a_{1} \\
a_{2} \\
a_{3} \\
a_{4} \\
a_{5}
\end{array}\right]}_{A} U_{n}=\underbrace{\left[\begin{array}{l}
b_{1} \\
b_{2} \\
b_{3} \\
b_{4} \\
b_{5}
\end{array}\right]}_{b} .
$$

Appling least squares to (14),

$$
U_{n}=\left(A^{T} A\right)^{-1} A^{T} b=\frac{a_{1} b_{1}+a_{2} b_{2}+a_{3} b_{3}+a_{4} b_{4}+a_{5} b_{5}}{a_{1}^{2}+a_{2}^{2}+a_{3}^{2}+a_{4}^{2}+a_{5}^{2}} \text {. }
$$

From (14),

$$
\begin{aligned}
& \frac{a_{1}}{a_{2}}=\frac{b_{1}}{b_{2}} \longrightarrow b_{2}=\frac{a_{2}}{a_{1}} b_{1}, \\
& \frac{a_{1}}{a_{3}}=\frac{b_{1}}{b_{3}} \longrightarrow b_{3}=\frac{a_{3}}{a_{1}} b_{1}, \\
& \frac{a_{1}}{a_{4}}=\frac{b_{1}}{b_{4}} \longrightarrow b_{4}=\frac{a_{4}}{a_{1}} b_{1}, \\
& \frac{a_{1}}{a_{5}}=\frac{b_{1}}{b_{5}} \longrightarrow b_{5}=\frac{a_{5}}{a_{1}} b_{1} .
\end{aligned}
$$

Placing (16) in (15),

$$
\begin{aligned}
U_{n} & =\frac{a_{1} b_{1}+\left(\left(a_{2}^{2} b_{1}\right) / a_{1}\right)+\left(\left(a_{3}^{2} b_{1}\right) / a_{1}\right)+\left(\left(a_{4}^{2} b_{1}\right) / a_{1}\right)+\left(\left(a_{5}^{2} b_{1}\right) / a_{1}\right)}{a_{1}^{2}+a_{2}^{2}+a_{3}^{2}+a_{4}^{2}+a_{5}^{2}}=\frac{\left(\left(b_{1}\right) / a_{1}\right)\left(a_{1}^{2}+a_{2}^{2}+a_{3}^{2}+a_{4}^{2}+a_{5}^{2}\right)}{a_{1}^{2}+a_{2}^{2}+a_{3}^{2}+a_{4}^{2}+a_{5}^{2}}=\frac{b_{1}}{a_{1}} \\
& =\frac{V_{n}\left(\left(\left(X_{r e f, n+1}-k_{X}\left(X_{r e f, n}-X_{n}\right)-X_{n}\right) / T_{S}\right)-\left(\mu_{1}\left(S_{1 e z, n}, P_{1, n}\right)+\mu_{2}\left(S_{2, n}, P_{1, n}\right)\right) X_{n}\right)}{-X_{n}} .
\end{aligned}
$$

Replacing (17) in (7),

$$
\begin{aligned}
X_{n+1}= & X_{r e f, n+1}-k_{X}\left(X_{r e f, n}-X_{n}\right) \\
& +T_{S}\left[\mu_{1}\left(S_{1 e z, n}, P_{1, n}\right)-\mu_{1}\left(S_{1, n}, P_{1, n}\right)\right] X_{n}
\end{aligned}
$$

Before, the tracking error for $X$ is defined as

$$
e_{X, n+1}=X_{r e f, n+1}-X_{n+1} .
$$

Substituting (18) in (19),

$$
\begin{aligned}
e_{X, n+1}= & k_{X}\left(X_{r e f, n}-X_{n}\right)-T_{S}\left[\mu_{1}\left(S_{1 e z, n}, P_{1, n}\right)\right. \\
& \left.-\mu_{1}\left(S_{1, n}, P_{1, n}\right)\right] X_{. n}
\end{aligned}
$$

The $\mu_{1}\left(S_{1 n}, P_{1 n}\right)$ Taylor approximation in the desired value $\mu_{1}\left(S_{1 e z n}, P_{1 n}\right)$ is

$$
\begin{array}{r}
\mu_{1}\left(S_{1, n}, P_{1, n}\right)=\mu_{1}\left(S_{1 e z, n}, P_{1, n}\right)+\frac{\mathrm{d} \mu_{1}\left(S_{1}, P_{1, n}\right)}{\mathrm{d} S_{1}} \mid \begin{array}{c}
\left(S_{1 n}-S_{1 e z, n}\right) \\
S_{1}=S_{e z, n}+\theta\left(S_{1, n}-S_{1 e z, n}\right)=S_{\theta}
\end{array} \\
\text { where } \longrightarrow 0<\theta<1
\end{array},
$$

Placing (21) in (20),

$$
\begin{aligned}
e_{X, n+1}= & k_{X}\left(X_{r e f, n}-X_{n}\right)-T_{S}\left[\mu_{1}\left(S_{1 e z, n}, P_{1, n}\right)\right. \\
& +\left.\frac{d \mu_{1}\left(S_{1}, P_{1, n}\right)}{d S_{1}}\right|_{S_{\theta}} \underbrace{\left(S_{1 n}-S_{1 e z, n}\right)}_{-e_{S_{1}, n}}-\mu_{1}\left(S_{1 e z, n}, P_{1, n}\right)] X_{n}, \\
e_{X, n+1}= & k_{X}\left(X_{r e f, n}-X_{n}\right)+\left.T_{S} \frac{d \mu_{1}\left(S_{1}, P_{1, n}\right)}{d S_{1}}\right|_{S_{\theta}} e_{S_{1}, n} X_{n} .
\end{aligned}
$$


TABLE 2: Nomenclature, description, and values of parameters.

\begin{tabular}{|c|c|c|}
\hline Parameter & Description & Value \\
\hline$\mu_{m 1}$ & Maximum specific growth rate coefficient for yeast on glucose $\left(\mathrm{h}^{-1}\right)$ & 1.8823 \\
\hline$\mu_{m 2}$ & Maximum specific growth rate coefficient for yeast on fructose $\left(h^{-1}\right)$ & 1.7098 \\
\hline$Y_{P 1 / S 1}$ & Yield coefficient for ethanol from glucose & 0.5085 \\
\hline$Y_{P 2 / S 1}$ & Yield coefficient for glycerol from glucose & 0.5331 \\
\hline$Y_{P 1 / S 2}$ & Yield coefficient for ethanol from fructose & 0.5098 \\
\hline$Y_{P 2 / S 2}$ & Yield coefficient for glycerol from fructose & 0.4462 \\
\hline$K_{S 1}$ & Saturation coefficient for cell growth on glucose $(\mathrm{g} / \mathrm{L})$ & 159.75 \\
\hline$K_{S 1 I}$ & Inhibition coefficient for cell growth on glucose $(\mathrm{g} / \mathrm{L})$ & 94.233 \\
\hline$K_{P 1}$ & Saturation coefficient for cell growth on ethanol $(\mathrm{g} / \mathrm{L})$ & 238.39 \\
\hline$K_{P 1 I}$ & Inhibition coefficient for cell growth on ethanol $(\mathrm{g} / \mathrm{l})$ & 2.7378 \\
\hline$K_{S 2}$ & Saturation coefficient for cell growth on fructose $(\mathrm{g} / \mathrm{L})$ & 0.0726 \\
\hline$K_{S 2 I}$ & Inhibition coefficient for cell growth on fructose $(\mathrm{g} / \mathrm{L})$ & 9.0048 \\
\hline$K_{P 2}$ & Saturation coefficient for cell growth on glycerol $(\mathrm{g} / \mathrm{L})$ & 35.958 \\
\hline$K_{P 2 I}$ & Inhibition coefficient for cell growth on glycerol (g/L) & 9.9722 \\
\hline$K_{S 1 P 1}$ & Saturation coefficient for ethanol production on glucose $(\mathrm{g} / \mathrm{L})$ & 1.3409 \\
\hline$k_{S 1 P 1}$ & Inhibition coefficient for ethanol production on glucose $(\mathrm{g} / \mathrm{L})$ & 18.612 \\
\hline$K_{S 2 P 1}$ & Saturation coefficient for ethanol production on fructose $(\mathrm{g} / \mathrm{L})$ & 0.9129 \\
\hline$k_{S 2 P 1}$ & Inhibition coefficient for ethanol production on fructose $(\mathrm{g} / \mathrm{L})$ & 1000 \\
\hline$K_{S 1 P 2}$ & Saturation coefficient for glycerol production on glucose $(\mathrm{g} / \mathrm{L})$ & 6.7116 \\
\hline$k_{S 1 P 2}$ & Inhibition coefficient for glycerol production on glucose $(\mathrm{g} / \mathrm{L})$ & 0.5863 \\
\hline$K_{S 2 P 2}$ & Saturation coefficient for glycerol production on fructose $(\mathrm{g} / \mathrm{L})$ & 0.4310 \\
\hline$k_{S 2 P 2}$ & Inhibition coefficient for glycerol production on fructose $(\mathrm{g} / \mathrm{L})$ & 1.150 \\
\hline$v_{S 1 P 1}$ & Coefficient of maximum specific ethanol production rate for yeast on glucose $\left(\mathrm{h}^{-1}\right)$ & 1.5051 \\
\hline$v_{S 2 P 1}$ & Coefficient of maximum specific ethanol production rate for yeast on fructose $\left(\mathrm{h}^{-1}\right)$ & 0.3321 \\
\hline$v_{S 1 P 2}$ & Coefficient of maximum specific glycerol production rate for yeast on glucose $\left(\mathrm{h}^{-1}\right)$ & 0.0023 \\
\hline$\nu_{S 2 P 2}$ & Coefficient of maximum specific glycerol production rate for yeast on fructose $\left(h^{-1}\right)$ & 0.1609 \\
\hline$\lambda$ & Proportion of glucose and fructose & 0.5 \\
\hline$S_{f}$ & Sugar total feed concentration $(\mathrm{g} / \mathrm{L})$ & 300 \\
\hline
\end{tabular}
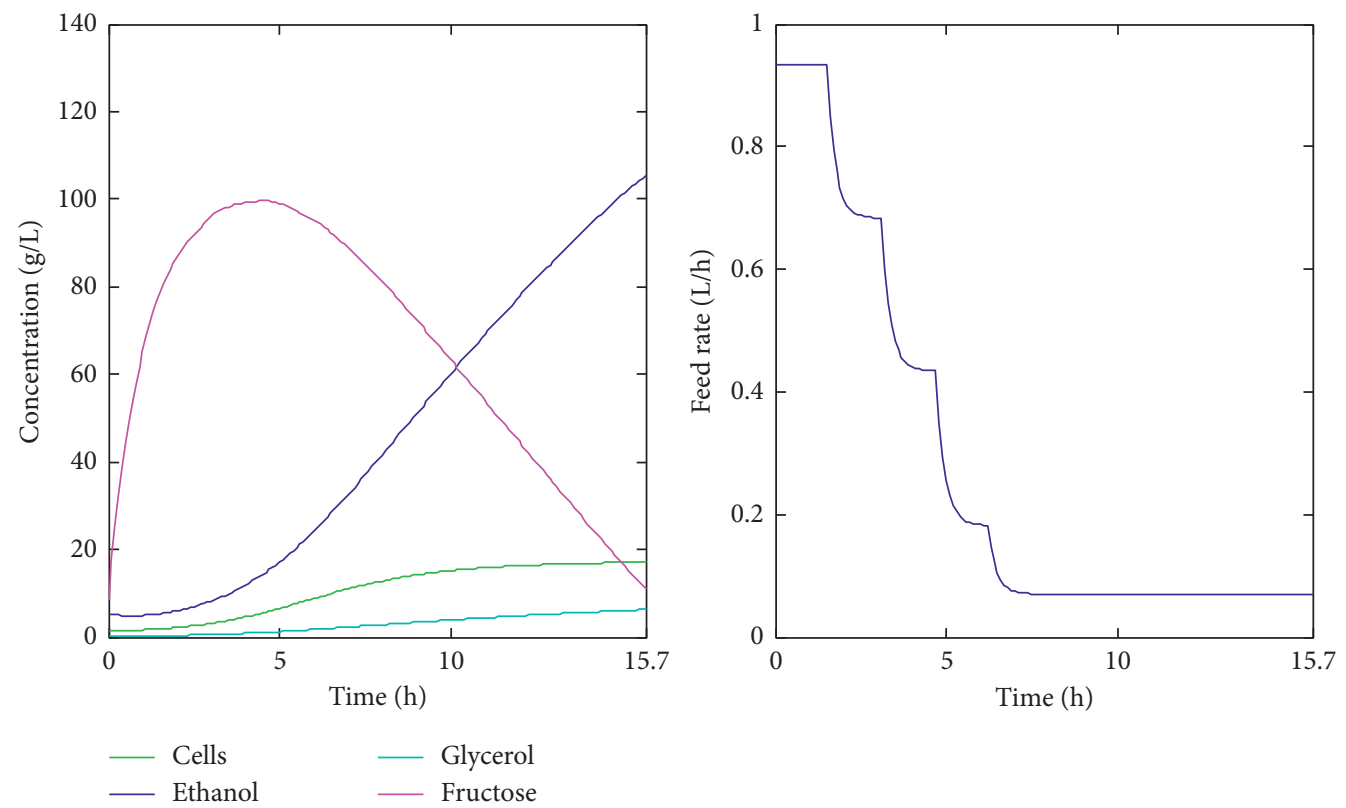

Figure 1: Cells, ethanol, glycerol, and fructose reference concentrations along the process. Reference feed flow rate. 
Following the same procedure for the other variables and joining the final expressions,

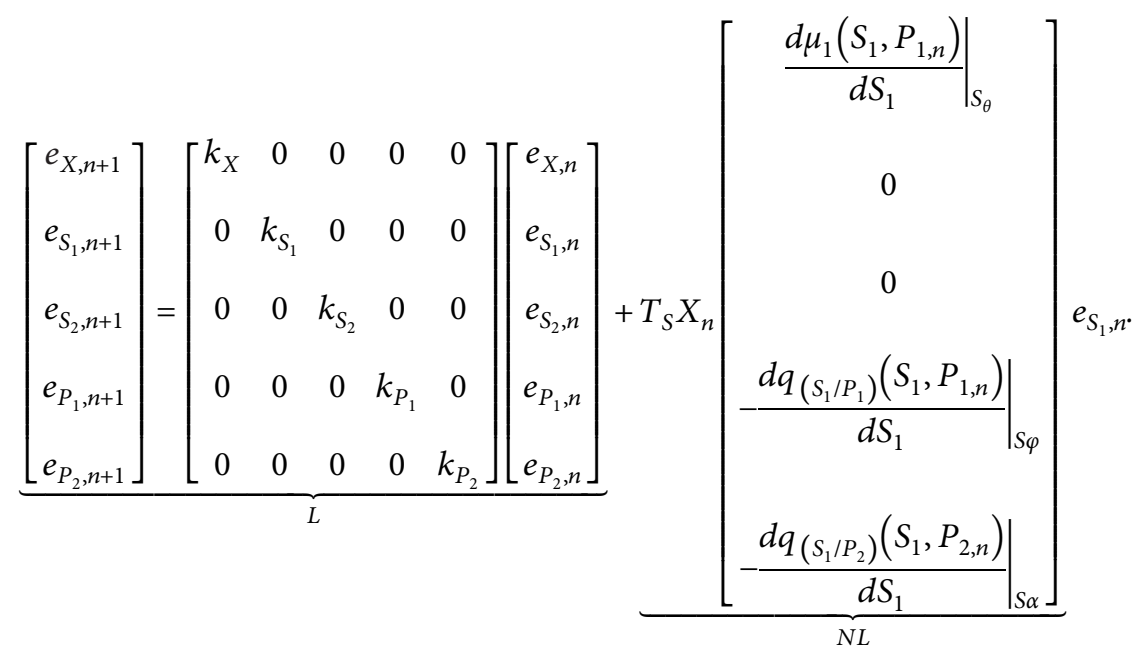

In equation (23), $L$ is a linear system and $N L$ is a bounded nonlinearity [50]. Note that if $k_{\sigma}=0$, the reference is reached in one step. Thus, if $0<k_{\sigma}<1$, the tracking error tends to zero when $n \longrightarrow \infty[50,57]$.

\subsection{Steps to Implement the Controller}

Step 1. Define $T_{s}, \sigma_{r e f}$, and $\sigma_{n}$.

Step 2. Discretize differential equations using some numerical methods, equation (3).

Step 3. Obtain the state variables in $n+1$ with equation (4).
Step 4. Define and calculate the sacrificed variable.

Step 5. Determine $U_{n}$ with least squares, equation (9).

Figure 2 outlines the control diagram.

\section{Control Structure Design under Additive Uncertainties}

3.1. Controller Design under Uncertainty. Next, uncertainties effect in the tracking error are considered by adding the terms $E_{\sigma, n}$ in (7):

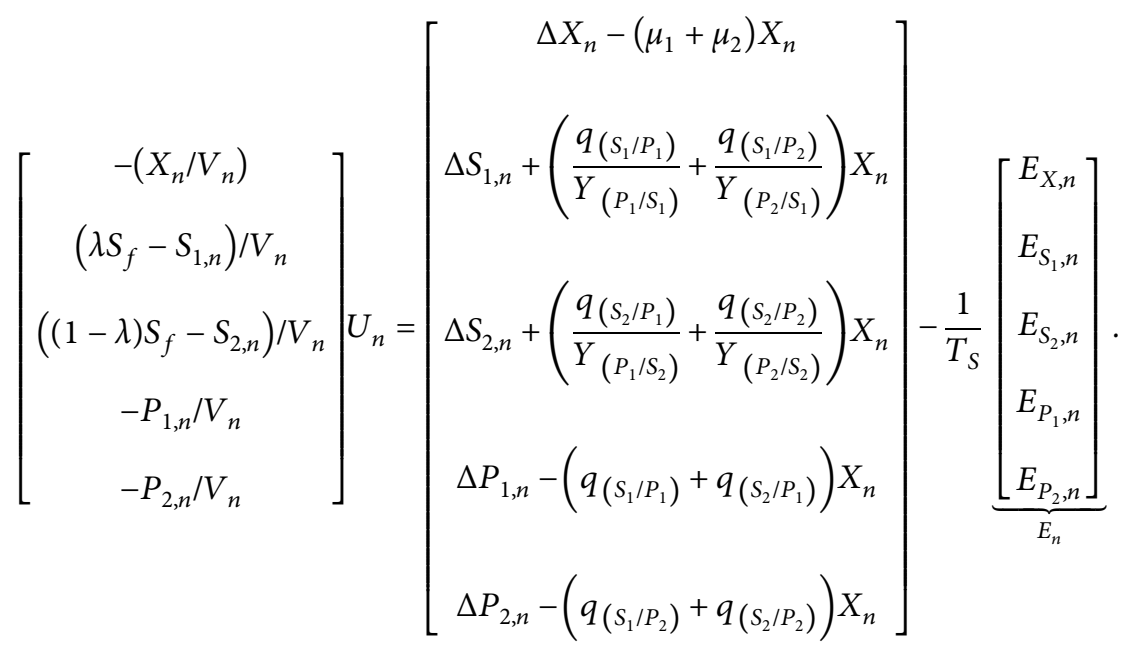

Additive uncertainty $\left(\boldsymbol{E}_{\boldsymbol{n}}\right)$ can be used to model several kinds of uncertainties as well as external perturbations (measurement errors are not considered). It might depend on the state variables and the system input. Moreover, considering a real plant like $z_{n+1}=f\left(z_{n}, u_{n}\right)$, therefore the additive uncertainty can be expressed as $\boldsymbol{E}_{\boldsymbol{n}}=f\left(z_{n}, u_{n}\right)-\widehat{f}$ 


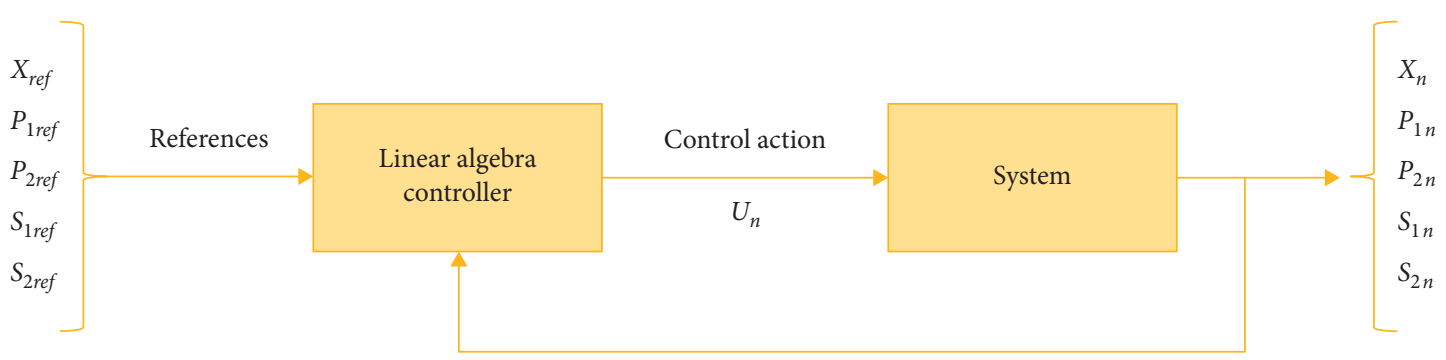

FIgURE 2: Control system diagram.

$\left(z_{n}, u_{n}\right)$, where $\hat{f}\left(z_{n}, u_{n}\right)$ is the discrete-time nonlinear system model. If $z$ and $u$ are assumed to be bounded and $f$ is Lipschitz [58], then $E_{\sigma, n}$ can be modeled as a bounded uncertainty $[59,60]$.
The uncertainties terms in (24) affect the error convergence to zero of the tracking error [50]. This can be observed following the same procedure as in Section 2.3 Theorem demonstration:

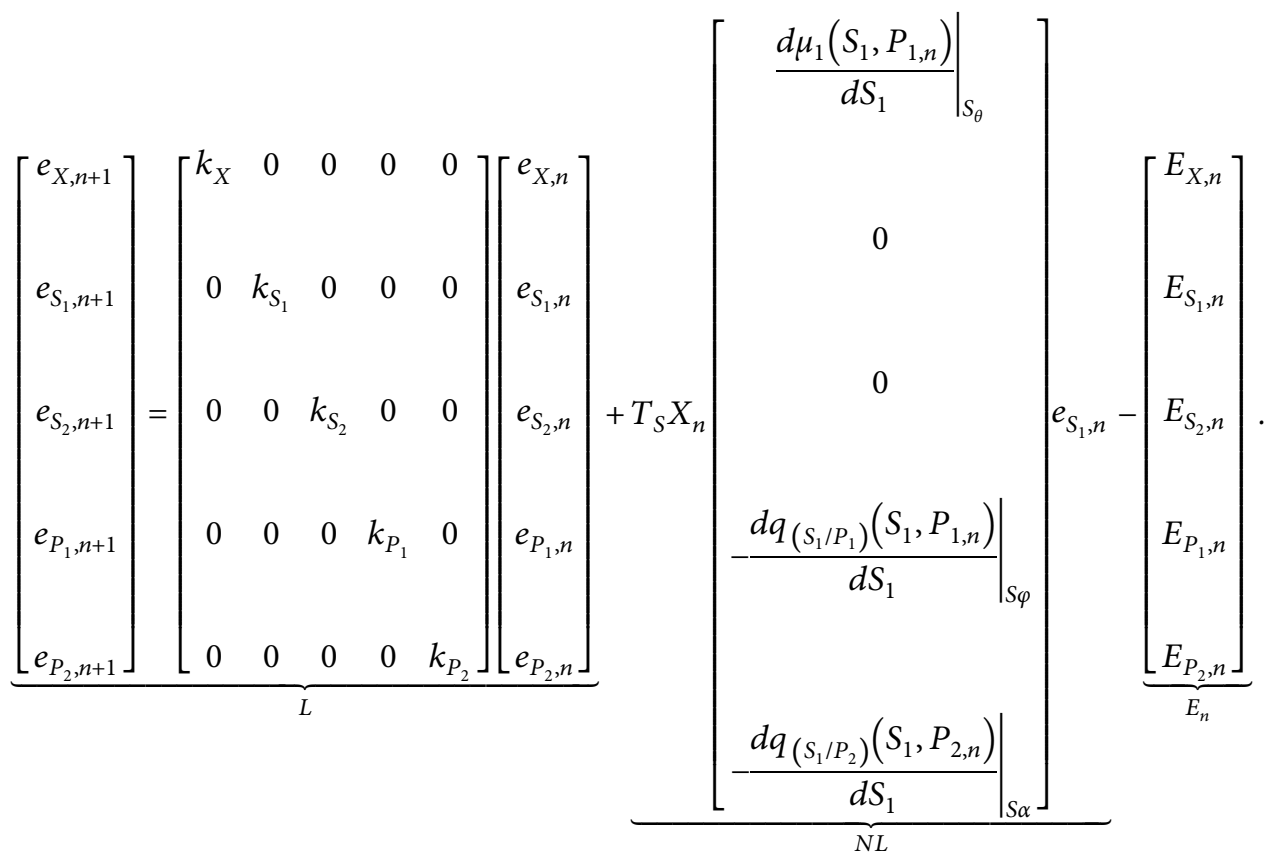

Comparing (25) with (23), the error nonconvergence to zero is noticed due to $\boldsymbol{E}_{\boldsymbol{n}}$ presence.

Therefore, the next step is $E_{\sigma, n}$ estimation to reduce their effect on the tracking error, achieving the convergence to zero.

3.2. Uncertainty Estimation. The following procedure, as the main contribution of this work, develops a control strategy based on linear algebra that reduces the effect of uncertainty in tracking error by its estimation using Newton's backward interpolation [61]. The advantage is the estimation development with an easy-to-understand numerical procedure, which does not add further complexity to the control methodology previously presented. Thus, $\boldsymbol{E}_{\boldsymbol{n}}$ is estimated with $\hat{E}_{n}$. Then, $\hat{E}_{n}$ is added in the control action calculation: 


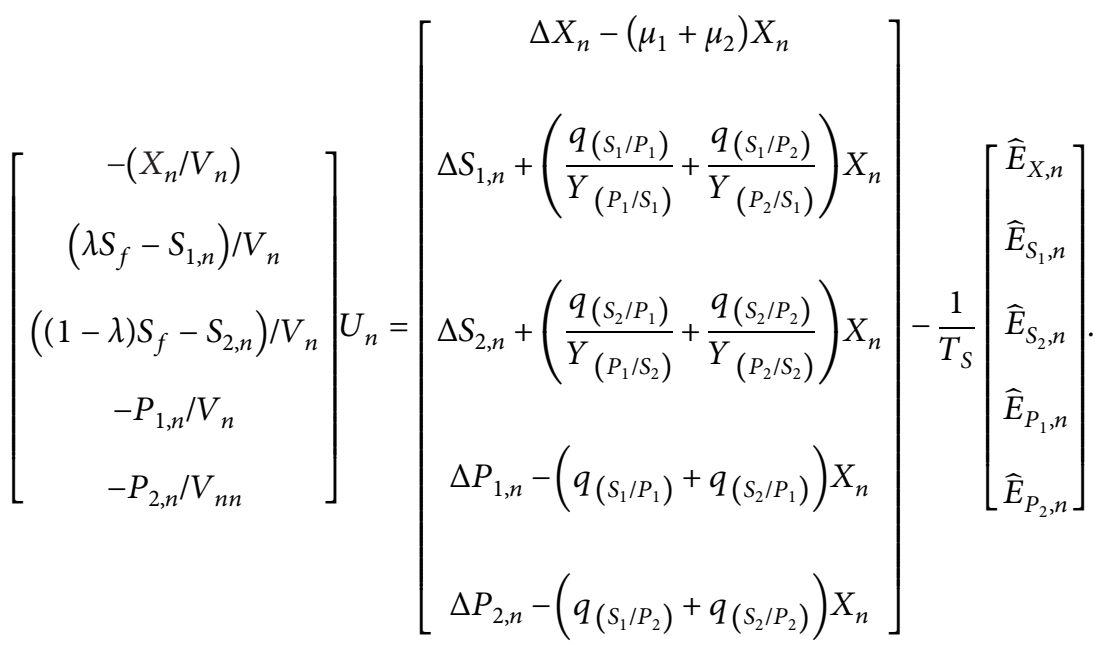

Taking into account that $\boldsymbol{E}_{\boldsymbol{\sigma}, \boldsymbol{n}}$ is unknown, but it is assumed as a polynomial, its differences can be defined as

$$
\begin{aligned}
\delta E_{\sigma, n} & =E_{\sigma, n+1}-E_{\sigma, n}, \\
\delta^{2} E_{\sigma, n} & =\delta\left(\delta E_{\sigma, n}\right)=\delta\left(E_{\sigma, n+1}-E_{\sigma, n}\right)=E_{\sigma, n+2}-2 E_{\sigma, n+1}+E_{\sigma, n}, \\
\delta^{q} E_{\sigma, n} & =\delta\left(\delta^{q-1} E_{\sigma, n}\right) .
\end{aligned}
$$

3.2.1. Constant Uncertainty. If $\boldsymbol{E}_{\boldsymbol{\sigma}, \boldsymbol{n}}$ is assumed as a constant, $\delta E_{\sigma, n}=0$. The uncertainty estimation is represented by

$$
E_{\sigma, n}=\sigma_{n+1}-\widehat{\sigma}_{n+1}
$$

where $\sigma$ is the real state variable and $\widehat{\sigma}$ represents the state variable calculated with equation (3). Then, the uncertainty is estimated with a zero-order approximation:

$$
\widehat{E}_{\sigma, n}=E_{\sigma, n} \text {. }
$$

Demonstration of error convergence to zero when uncertainties are considered:

Replacing the control action given by equation (26) in (24) and applying the same steps described in Section 2.3 demonstration,

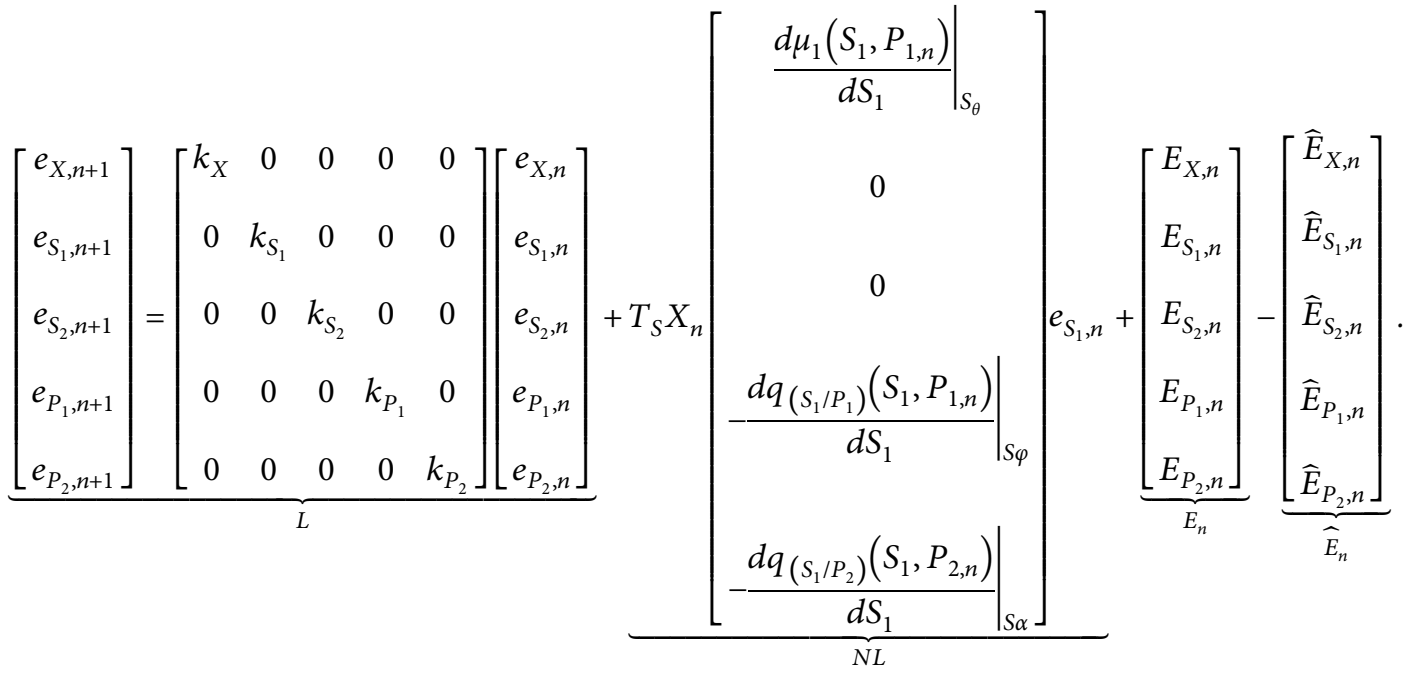

Remark 1. If $\mathrm{E} \sigma, n=c$, where $c$ is a constant value, and $\hat{\mathrm{E}} \sigma, \mathrm{n}$ is calculated with equation (29), then $\delta E_{\sigma, n}=0$.

Thus, if $\boldsymbol{E}_{\boldsymbol{n}}$ is unknown and each component is an m-order polynomial, $\boldsymbol{E}_{\boldsymbol{n}}=\hat{\boldsymbol{E}}_{\boldsymbol{n}}$, then $\boldsymbol{E}_{\boldsymbol{n}}$ and $\hat{\boldsymbol{E}}_{\boldsymbol{n}}$ can be simplified from (30). Therefore, it is demonstrated that the tracking error tends to zero with the process progress.
3.2.2. Linear Uncertainty. If $\boldsymbol{E}_{\boldsymbol{\sigma}, \boldsymbol{n}}$ is supposed as a linear function, then $\delta^{2} E_{\sigma, n}=0$. Following the same reasoning as in 3.2.1, $\hat{\boldsymbol{E}}_{\boldsymbol{\sigma}, \boldsymbol{n}}$ is defined as

$$
\widehat{E}_{\sigma, n}=E_{\sigma, n}+E_{\sigma, n}-E_{\sigma, n-1} .
$$

Following the same steps of 3.2.1, the error convergence to zero is demonstrated. 


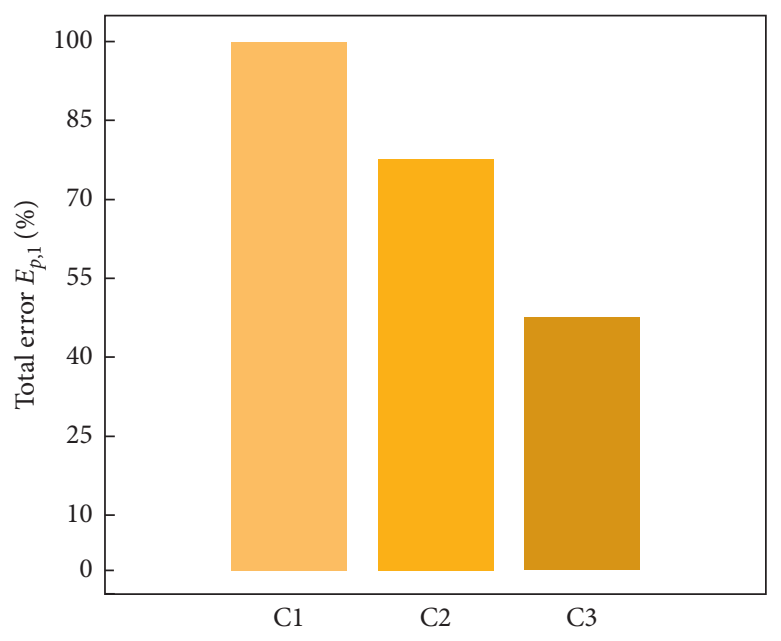

(a)

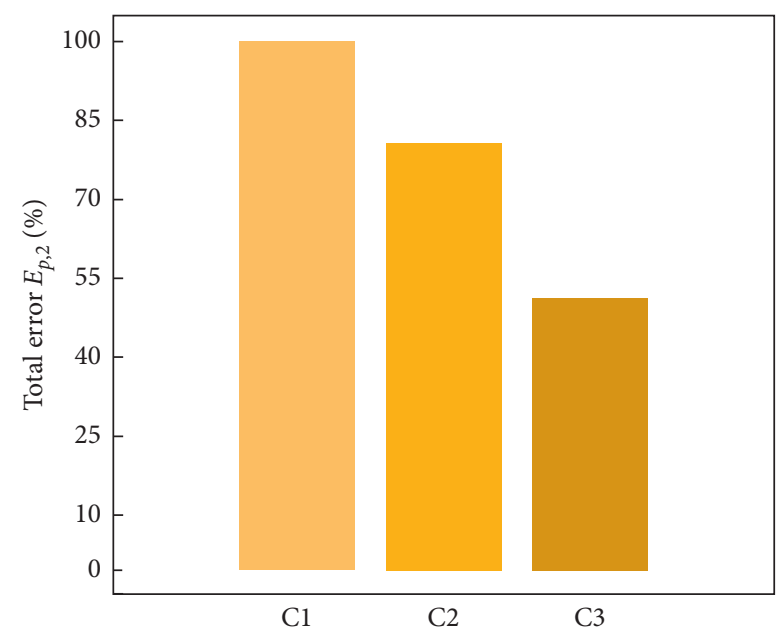

(b)

Figure 3: Controllers comparison. Total error decrease: (a) Ep 1 (12); (b) Ep 2 (13).

TABLE 3: Parametric uncertainty of $\pm 10 \%$.

\begin{tabular}{lc}
\hline Controller & Total error range \\
\hline C1 & $\mathbf{0 . 5 2 6 7 - 0 . 0 0 9 8}$ \\
C2 & $\mathbf{0 . 2 9 5 8 - 0 . 0 0 5 6}$ \\
C3 & $\mathbf{0 . 0 8 1 2 - 0 . 0 0 4 9}$ \\
\hline
\end{tabular}

3.2.3. Polynomial Uncertainty. In this case, $\boldsymbol{E}_{\boldsymbol{\sigma}, \boldsymbol{n}}$ is supposed as an $m$-order polynomial function. Then, if $q>\mathrm{m}$, $\delta^{q} E_{\sigma, n}=0$. Using the same procedure explained before, the representation of $\hat{\boldsymbol{E}}_{\boldsymbol{\sigma}, \boldsymbol{n}}$ is generically expressed as

$$
\widehat{E}_{\sigma, n}=\sum_{j=0}^{m} \sum_{i=0}^{j}\left(\begin{array}{l}
j \\
i
\end{array}\right)(-1)^{i} \frac{E_{\sigma, n-i-1}}{j !} .
$$

3.3. Controller Parameter Selection. To select the best $k_{\sigma}$ values (between zero and one for stability guarantee), as many authors recommend [62-64], the Monte Carlo algorithm is used following the procedure described in 2.3. Therefore, 1000 simulations were done to find the parameters for three different controllers, the original, described in [50] (C1), other with a zero-order estimator (C2), and the last with a first-order estimator (C3). Figure 3 shows the difference between the three controllers. Note the error improvement evidenced with both indexes ((12) and (13)), with $\mathrm{C} 2$, the total error $E_{p, 1}$ decreases by $22.22 \%$ and $E_{p, 2}$ by $19.31 \%$ compared to $C 1$, while with $C 3$, the total error is reduced by $52.38 \%$ and $48.73 \%$, respectively, concerning $C 1$. Due to the results similarity with both indexes, from now on only $E_{p, 1}$ will be used to evaluate the algorithms.

\section{Results and Discussion}

In the following section, two important tests are developed to demonstrate the proposed estimation effectiveness. First, the Monte Carlo Algorithm is applied to test the controller operation under parametric uncertainty. Second, two different perturbations in the control action are added. Furthermore, both above tests are performed simultaneously and are compared with the performance of two other controllers using another methodology [65]. In this section, the original controller is noted as $\mathrm{C} 1$, the controller with a zero-order estimation is $\mathrm{C} 2$, and the controller with a firstorder estimator is C3.

4.1. Simulation under Parametric Uncertainties. In all bioprocess, model parameters may vary in an unpredictable way [66]. This can lead to structural instability in the system dynamical behavior [15]. Therefore, a strict and efficient control system is required to deal with this problem.

In several research fields, probabilistic methods are useful for dealing with problems related to the robustness of systems affected by uncertainties [55]. Particularly, Monte Carlo Randomized Algorithm has been used for uncertainty quantification in many applications [67-69]. In this paper, the Monte Carlo Randomized Algorithm is applied using the procedure described in 2.3. The number of simulations, $N=1000$, is obtained with equation (10), adopting a confidence $(\delta)$ of 0.01 and an accuracy $(\varepsilon)$ of 0.005 . Therefore, the following test demonstrates the technique success from a statistical point of view [70-72].

In a simulation, a way to quantify uncertainties and perturbations is to specify the parameters real range of variation instead of using a constant value with greater error [73]. Hunag et al. [36] specified, in Table 1 of their work, the parameters confidence intervals for the ethanol process under study. For this test, in each simulation, all the system parameters are randomly changed by $\pm 10 \%$ of their original range value (Table 1 of [36]). Then, the total error is calculated with equation (12). Table 3 shows the error range for each controller. Note how the total error range considerably decreases and maintains bounded to lower values when the estimation order increases. Figure 4 shows the total error for 1000 simulations to evaluate the three-controller 

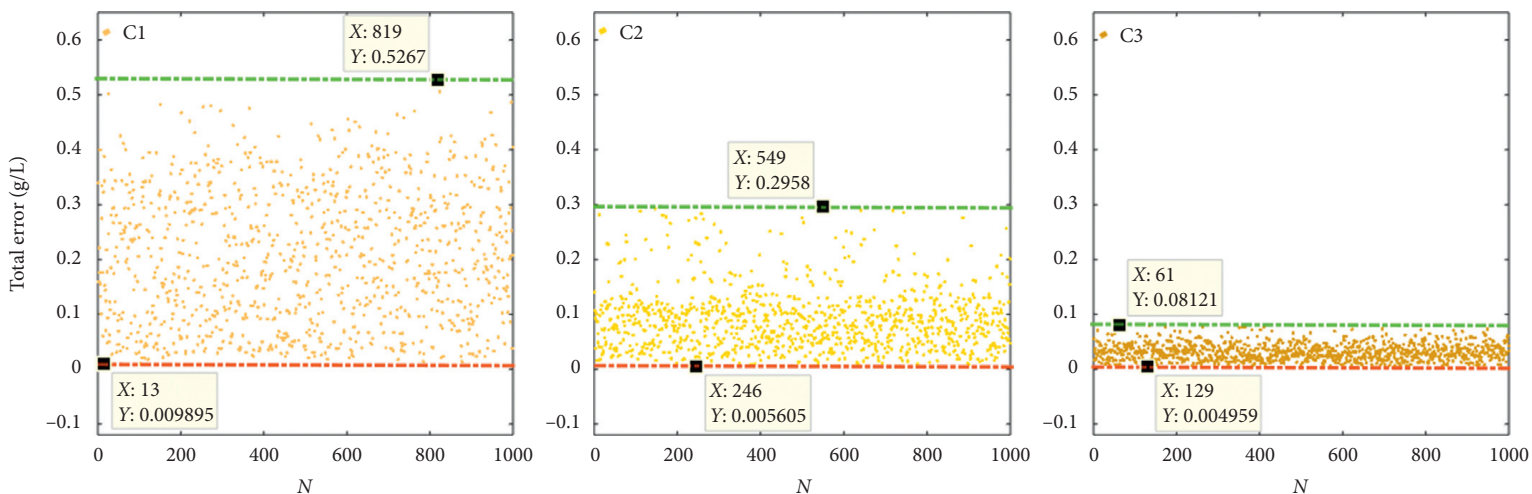

FiguRe 4: Total error for 1000 simulations under parametric uncertainty ( $\pm 10 \%)$. (C1) Original controller; (C2) controller with a zero-order estimation; and (C3) controller with first-order estimator.

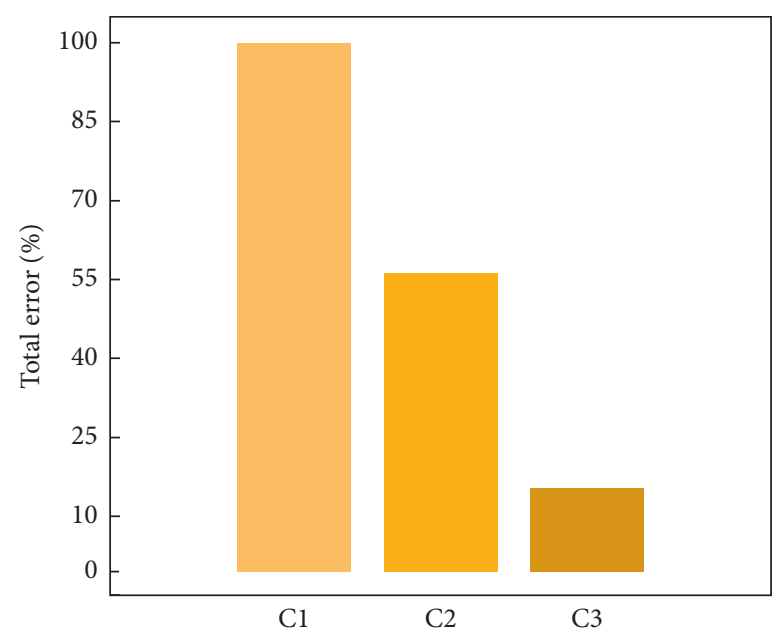

FIGURE 5: Controllers comparison of maximum total error.

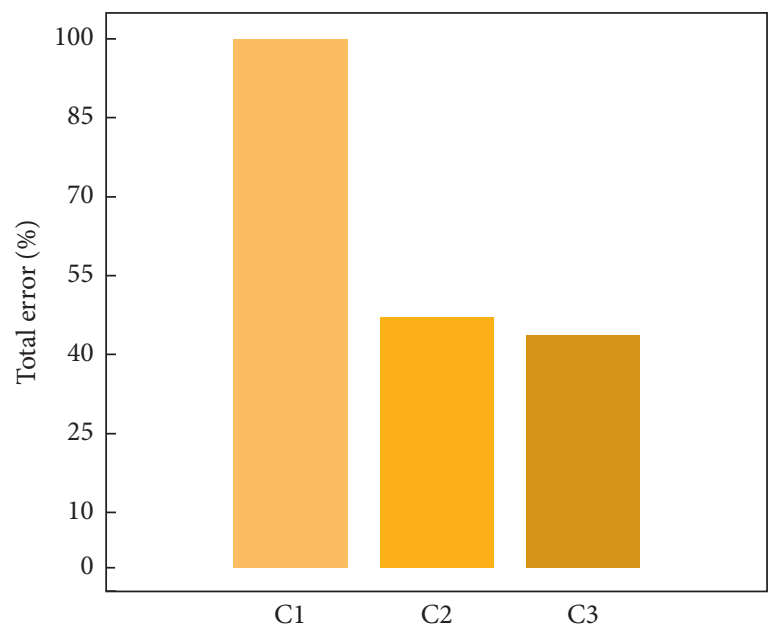

FiguRE 6: Total error decrease when the controllers are tuned considering the worst situation of $C 1$ (total error: $C 1=0.1334, C 2=0.0633$, C3 $=0.0585)$. 

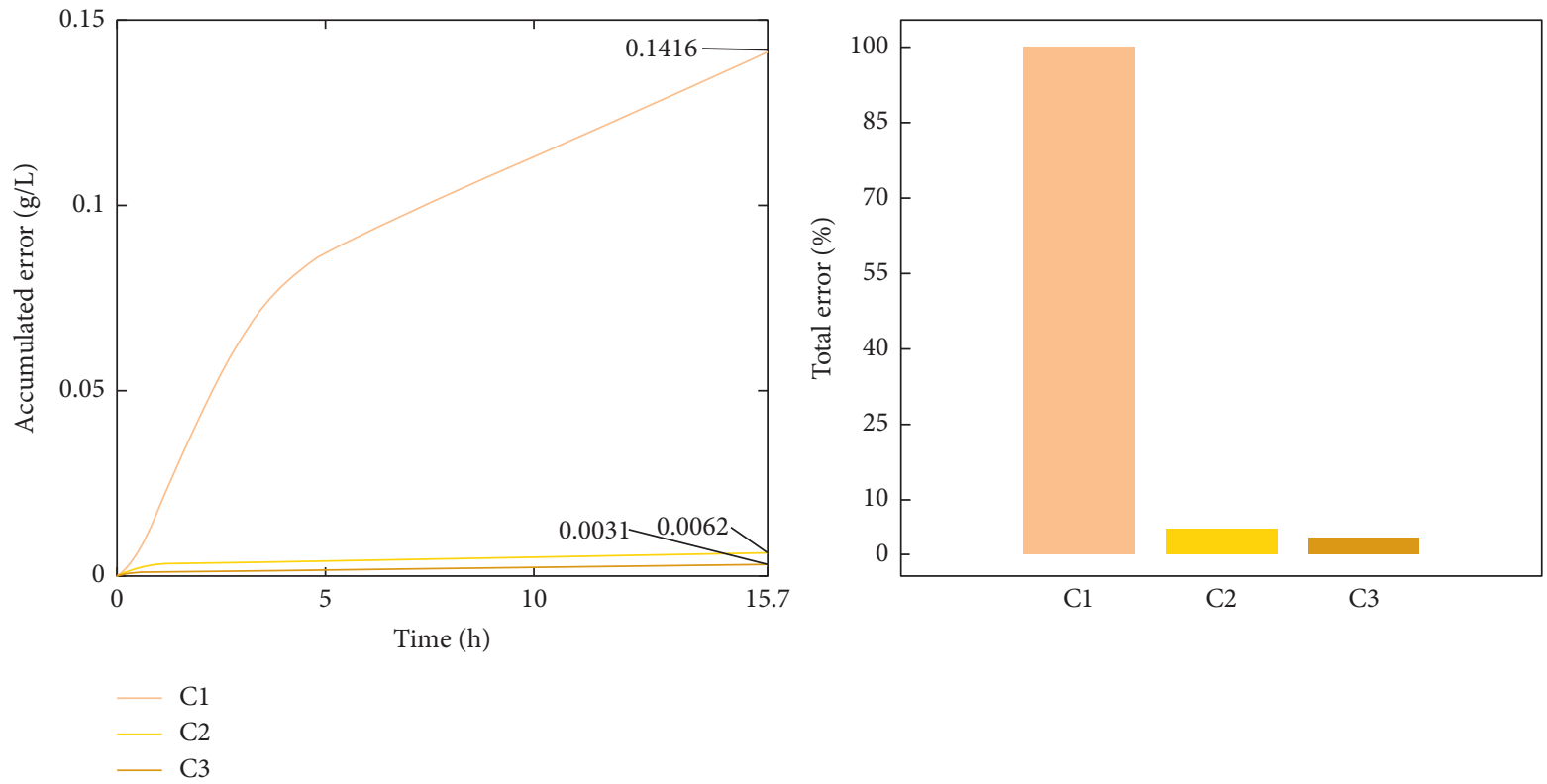

Figure 7: Errors comparison for the three controllers: (C1) original controller; (C2) controller with a zero-order estimation; (C3) controller with the first-order estimator.

TABLE 4: Total error comparison under normal conditions.

\begin{tabular}{llllr}
\hline & & C1 & C2 & \\
\hline \multirow{2}{*}{ Total error } & a) & 0.0063 & 0.0049 & 0.0030 \\
& b) & 0.1416 & 0.0062 & 0.0031 \\
\hline
\end{tabular}

a) Tuned in normal conditions; b) tuned considering the worst situation of 4.1 for C1.

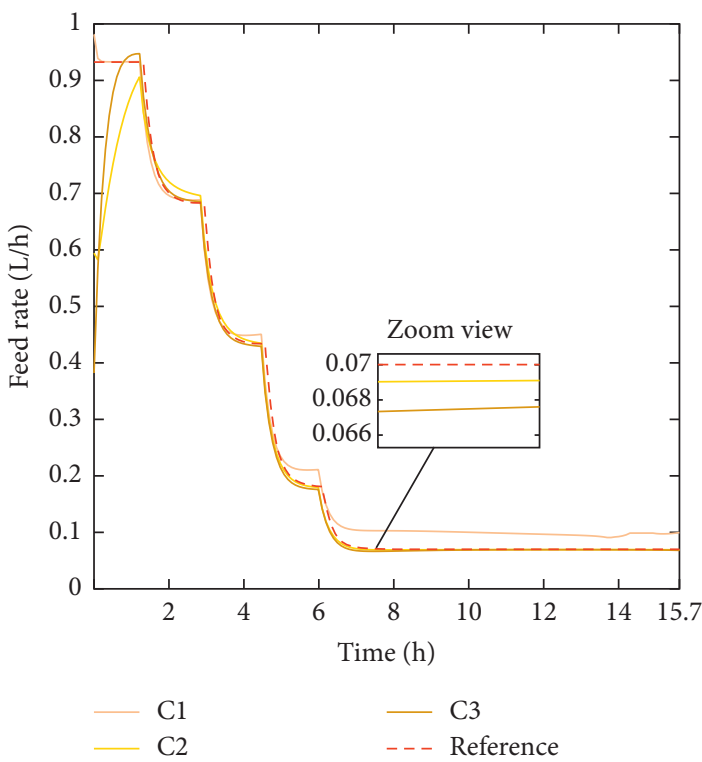

(a)

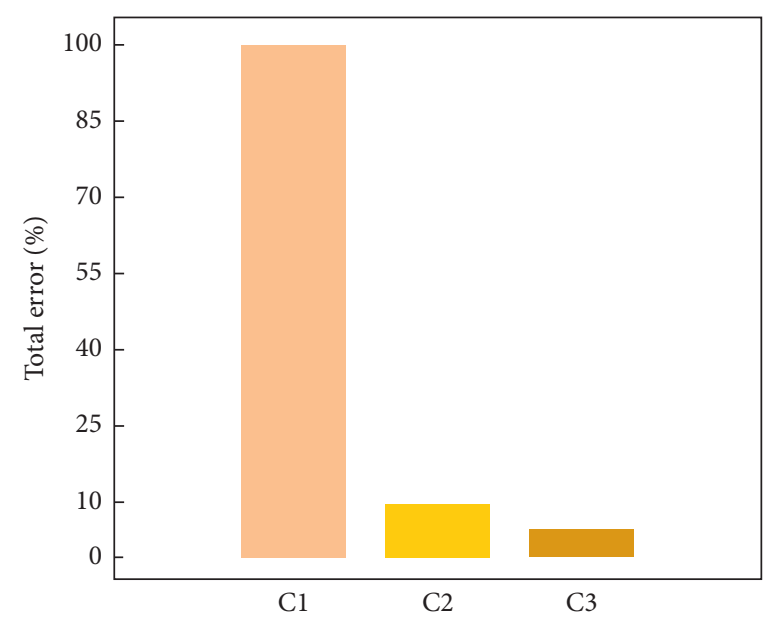

Figure 8: (a) Controllers response to a step perturbation addition in the control action. (b) Total error comparison $(\mathrm{C} 1=1.5968$, $\mathrm{C} 2=0.1523, \mathrm{C} 3=0.0801)$. 


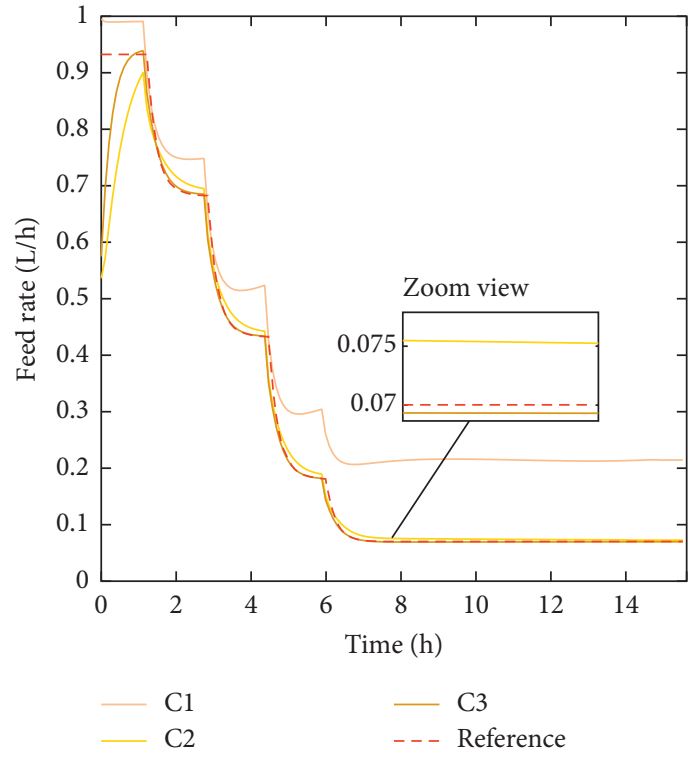

(a)

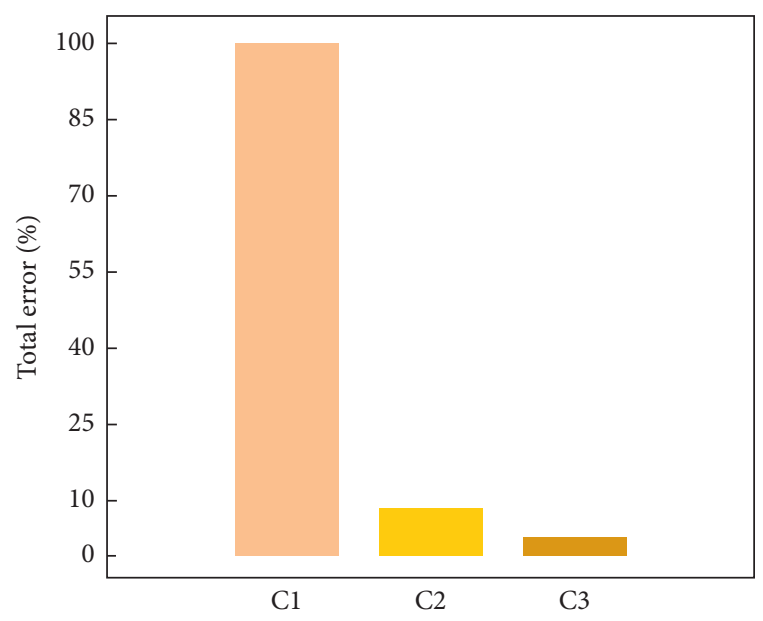

(b)

FiguRE 9: (a) Controllers response to a step and ramp perturbation addition in the control action. (b) Total error comparison $(\mathrm{C} 1=6.9351$, $\mathrm{C} 2=0.6542, \mathrm{C} 3=0.1977)$.

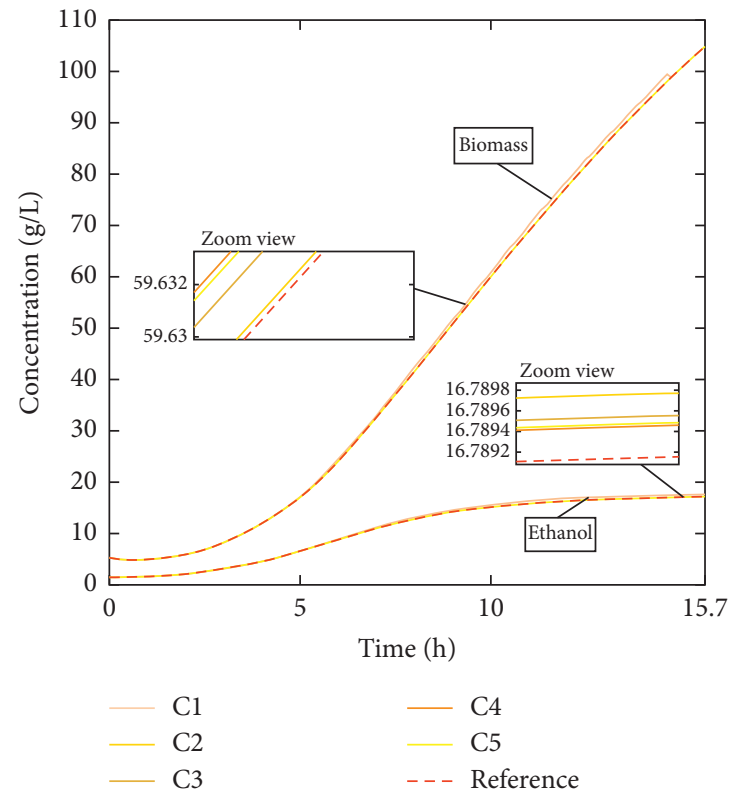

(a)

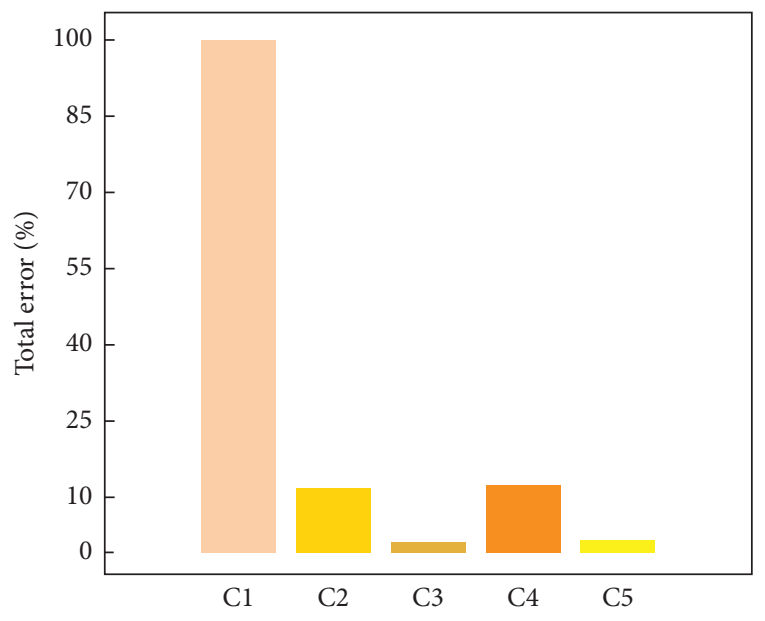

Figure 10: (a) Controllers response to parametric uncertainty and a step and ramp perturbation addition in the control action. (b) Total error comparison.

performance under parametric uncertainty. As can be seen, the total tracking error range is visibly reduced.

Expressing the total error for each case into a percentage can easily quantify the controller improvement when estimators are incorporated. Figure 5 suggests the better performance of the controllers $C 2$ and $C 3$ over $C 1$. The worst case presented for $C 2$ has a total error of $43.83 \%$ lower than that of the worst situation of $C 1$, while the maximum error presented with $C 3$ is $84.58 \%$ less than that of $C 1$. 
Considering Theorem 1 of [55], as the tracking error (equation (11)) for 1000 simulations remains bounded, C2 and $C 3$ controllers operation will be satisfactory with $99 \%$ of probability while the parameters vary within a $\pm 10 \%$ range.

4.2. Simulation for Uncertainties Prevention. In the following test, controllers are tuned taking into account the worst possible situation presented in 4.1 for $C 1$, to prevent it. Figure 6 shows the total error decreases when each controller is tuned. Note how even considering the most problematic situation of the system, the performance error can be reduced by $52.55 \%$ just by adding a zero-order estimator and by $56.15 \%$ with a first-order one.

Then, the controllers using the chosen parameters were tested under normal operation conditions, demonstrating that their performance is not negatively affected. Figure 7 compares the accumulated error for the three controllers. Moreover, total errors $(C 1=0.1416, \quad C 2=0.0062$, $C 3=0.0031)$ contrast is shown.

This test demonstrates another advantage of the proposed estimation technique. Table 4 compares the errors of Figure 3 with those of Figure 7. In both cases, the controllers are tested under normal conditions; however, the difference lies in the tuning conditions considered. Analyzing Table 2, it can be observed that $C 2$ and $C 3$ controllers present similar results, which does not happen with $C 1$. Therefore, it can be said that the operation of $C 2$ and $C 3$ will have a minimum error over the entire range of possible uncertainties between the nominal system parameters values and their worst variation.

\subsection{Simulation Adding Perturbations in the Control Action.} In this test, a hypothetical situation that may produce an unexpected variation in the production is simulated. Firstly, a $-30 \%$ step perturbation in the bioreactor feed rate is added to evaluate the response of controllers. Secondly, a ramp disturbance is added to the step perturbation previously presented. Figures 8 and 9 show the control action variation compared to the reference and the percentage error, considering $\mathrm{C} 1$ error as $100 \%$. Note how the total error improves when the new algorithm is applied. In the first test, it is reduced by $90.46 \%$ with C2 and by $94.99 \%$ with C3, while in the second test, the results are improved $91.87 \%$ with C2 and 97.15\% with C3.

4.4. Simulation Adding Parametric Uncertainties and Perturbations in the Control Action. This latest test aims to demonstrate how the controllers can fix a large drift. In this way, 4.1 and 4.3 disturbances are considered simultaneously. Besides, the methodology proposed in [55] was also implemented to this ethanol bioprocess [65] and the results obtained are compared with those of the proposed technique. Figure 10 shows the biomass and ethanol profiles obtained with each controller throughout the process and a comparison of the errors. Here, C4 refers to a controller with one integrator and C5 with two ones. An improvement can be seen with the use of estimators concerning integrators
$(\mathrm{C} 1=100 \% ; \mathrm{C} 2=12.5 \% ; \mathrm{C} 3=1.9 \% ; \mathrm{C} 4=13.1 \%$; $\mathrm{C} 5=2.4 \%)$. Furthermore, the error estimation has the advantage that it does not increase the order of the system by incorporating the estimation term and does not modify the form tuning as it does the integrators methodology, making mathematical development simpler.

\section{Conclusions}

This paper presents an improvement for a tracking control strategy previously published [50]. This technique lets tracking reference concentration profiles, even in the presence of model uncertainties and external perturbances. To consider those uncertainties, a new term is included in the mathematical model. The error estimation is approximated with Newton's backward interpolation. In this manuscript, the main contribution is to decrease additive uncertainties effect on the tracking error without increasing the controller mathematical complexity. Moreover, the controller tuning is simpler than in conventional controllers, since varying the parameters between zero and one the error convergence to zero is achieved.

The Monte Carlo Randomized Algorithm is used to tune the controllers and carry out the tests with parametric uncertainty. Those tests show the effectiveness of this methodology, which was demonstrated in Sections 3 and 4.

Comparing with other methodologies that deal with similar uncertain control problems, such as [74-79], the proposed controller presents the advantage of avoiding the stochastic modeling needed to deal with parameters under perturbation of white noise. Besides, this nonlinear control does not require a great mathematical effort and does not add significant complexity to the original controller.

\section{Data Availability}

The data used to support the findings of this study are included within the article.

\section{Conflicts of Interest}

The authors declare that they have no conflicts of interest.

\section{Acknowledgments}

The National Council of Scientific and Technological Research (CONICET) and the Chemical Engineering Institute (IIQ) from the National University of San Juan contributed to this investigation.

\section{References}

[1] M. G. Mangesh and A. K. Jana, ““"A comparison of three sets of DSP algorithms for monitoring the production of ethanol in a fed-batch baker's yeast fermenter," Measurement, vol. 41, pp. 970-985, 2008.

[2] T. L. Fujiki, M. R. G. Sanzovo, M. S. Leite, F. V. Silva, and A. M. F. Fileti, "Optimizing control action online using a neural model and the solver of an electronic worksheet," Computer Aided Chemical Engineering, vol. 27, pp. 1461-1466, 2009. 
[3] A. M. Nielsen and A. Feilberg, "Anaerobic digestion of energy crops in batch," Biosystems Engineering, vol. 112, no. 3, pp. 248-251, 2012.

[4] S. Liu, "Fed-batch cultivation," in Bioprocess Engineering, pp. 663-694, Elsevier, Amsterdam, Netherlands, 2013.

[5] S. Ochoa, "A new approach for finding smooth optimal feeding profiles in fed-batch fermentations," Biochemical Engineering Journal, vol. 105, pp. 177-188, 2016.

[6] C. Liu, Z. Gong, B. Shen, and E. Feng, "Modelling and optimal control for a fed-batch fermentation process," Applied Mathematical Modelling, vol. 37, no. 3, pp. 695-706, 2013.

[7] H. Jin, X. Chen, J. Yang, L. Wu, and L. Wang, "Hybrid intelligent control of substrate feeding for industrial fed-batch chlortetracycline fermentation process," ISA Transactions, vol. 53, no. 6, pp. 1822-1837, 2014.

[8] J. A. Baeza, "Principles of bioprocess control," in Current Developments in Biotechnology and Bioengineering, M. Á, G. Sanromán Du, and A. Pandey, Eds., Elsevier, Amsterdam, Netherlands, pp. 527-561, 2017.

[9] K. Zhou, J. C. Doyle, and K. Glover, "Prentice hall New Jersey," Robust and Optimal Control, vol. 40, 1996.

[10] J. Hess and O. Bernard, "Design and study of a risk management criterion for an unstable anaerobic wastewater treatment process," Journal of Process Control, vol. 18, no. 1, pp. 71-79, 2008.

[11] M. Koutinas, A. Kiparissides, E. N. Pistikopoulos, and A. Mantalaris, "Bioprocess systems engineering: transferring traditional process engineering principles to industrial biotechnology," Computational and Structural Biotechnology Journal, vol. 3, pp. 1-9, 2012.

[12] G. Bellu, M. P. Saccomani, S. Audoly, and L. D’Angiò, "DAISY: a new software tool to test global identifiability of biological and physiological systems," Computer Methods and Programs in Biomedicine, vol. 88, no. 1, pp. 52-61, 2007.

[13] S. Régis, A. Doncescu, and N. Goma, "Bioprocess diagnosis based on the empirical use of distance measures in the theory of belief functions," Engineering Applications of Artificial Intelligence, vol. 28, pp. 165-173, 2014.

[14] R. Morales-Rodriguez, A. S. Meyer, K. V. Gernaey, and G. Sin, "A framework for model-based optimization of bioprocesses under uncertainty: lignocellulosic ethanol production case," Computers \& Chemical Engineering, vol. 42, pp. 115-129, 2012.

[15] G. Lara-Cisneros, R. Femat, and E. Pérez, "On dynamical behaviour of two-dimensional biological reactors," International Journal of Systems Science, vol. 43, no. 3, pp. 526-534, 2012.

[16] Z. K. Nagy and R. D. Braatz, "Open-loop and closed-loop robust optimal control of batch processes using distributional and worst-case analysis," Journal of Process Control, vol. 14, no. 4, pp. 411-422, 2004.

[17] H. De Battista, J. Picó, and E. Picó-Marco, "Nonlinear PI control of fed-batch processes for growth rate regulation," Journal of Process Control, vol. 22, no. 4, pp. 789-797, 2012.

[18] E. Petre and D. Selişteanu, "A multivariable robust-adaptive control strategy for a recycled wastewater treatment bioprocess," Chemical Engineering Science, vol. 90, pp. 40-50, 2013.

[19] R. Simutis and A. Lübbert, "Bioreactor control improves bioprocess performance," Biotechnology Journal, vol. 10, no. 8, pp. 1115-1130, 2015.

[20] B. Liu, "Uncertainty theory," in Uncertainty Theory, pp. 205-234, Springer, Berlin, Germany, 2007.
[21] Y. Zhu, "Uncertain fractional differential equations and an interest rate model," Mathematical Methods in the Applied Sciences, vol. 38, no. 15, pp. 3359-3368, 2015.

[22] T. Jin, H. Xia, and H. Chen, "Optimal control problem of the uncertain second-order circuit based on first hitting criteria," Mathematical Methods in the Applied Sciences, vol. 44, no. 1, pp. 882-900, 2021.

[23] T. Jin, H. Ding, H. Xia, and J. Bao, "Reliability index and Asian barrier option pricing formulas of the uncertain fractional first-hitting time model with Caputo type," Chaos, Solitons \& Fractals, vol. 142, Article ID 110409, 2021.

[24] T. Jin, H. Ding, B. Li, H. Xia, and C. Xue, "Valuation of interest rate ceiling and floor based on the uncertain fractional differential equation in Caputo sense," Journal of Intelligent \& Fuzzy Systems, vol. 40, 2017.

[25] A. Donoso-Bravo, J. Mailier, C. Martin, J. Rodríguez, C. A. Aceves-Lara, and A. V. Wouwer, "Model selection, identification and validation in anaerobic digestion: a review," Water Research, vol. 45, no. 17, pp. 5347-5364, 2011.

[26] P. Wechselberger, A. Seifert, and C. Herwig, "PAT method to gather bioprocess parameters in real-time using simple input variables and first principle relationships," Chemical Engineering Science, vol. 65, no. 21, pp. 5734-5746, 2010.

[27] E. Balsa-Canto, A. A. Alonso, and J. R. Banga, "An iterative identification procedure for dynamic modeling of biochemical networks," BMC Systems Biology, vol. 4, p. 11, 2010.

[28] C. Vilas, A. Arias-Méndez, M. R. García, A. A. Alonso, and E. Balsa-Canto, "Toward predictive food process models: a protocol for parameter estimation," Critical Reviews in Food Science and Nutrition, vol. 58, pp. 436-449, 2018.

[29] C. Liu, Z. Gong, K. L. Teo, and E. Feng, "Multi-objective optimization of nonlinear switched time-delay systems in fedbatch process," Applied Mathematical Modelling, vol. 40, no. 23-24, pp. 10533-10548, 2016.

[30] G. Scaglia, V. Mut, A. Rosales, and O. Quintero, "Tracking control of a mobile robot using linear interpolation," IMAACA, vol. 1, pp. 11-15, 2007.

[31] R. Hille and H. M. Budman, "Run-to-Run optimization of batch processes using set-based constraints," IFAC-PapersOnLine, vol. 50, no. 1, pp. 4678-4683, 2017.

[32] R. Hille, J. Mandur, and H. M. Budman, "Robust batchto-batch optimization in the presence of model-plant mismatch and input uncertainty," AIChE Journal, vol. 63, no. 7, pp. 2660-2670, 2017.

[33] J. Camacho, D. Lauri, B. Lennox, M. Escabias, and M. Valderrama, "Evaluation of smoothing techniques in the run to run optimization of fed-batch processes with u-PLS," Journal of Chemometrics, vol. 29, no. 6, pp. 338-348, 2015.

[34] M. Luna and E. Martínez, "A bayesian approach to run-to-run optimization of animal cell bioreactors using probabilistic tendency models," Industrial \& Engineering Chemistry Research, vol. 53, no. 44, pp. 17252-17266, 2014.

[35] C.-L. Ko and F.-S. Wang, "Run-to-run fed-batch optimization for protein production using recombinant Escherichia coli," Biochemical Engineering Journal, vol. 30, no. 3, pp. 279-285, 2006.

[36] W.-H. Hunag, G. S. Shieh, and F.-S. Wang, "Optimization of fed-batch fermentation using mixture of sugars to produce ethanol," Journal of the Taiwan Institute of Chemical Engineers, vol. 43, no. 1, pp. 1-8, 2012.

[37] Q. Lin, R. Loxton, C. Xu, and K. L. Teo, "Parameter estimation for nonlinear time-delay systems with noisy output measurements," Automatica, vol. 60, pp. 48-56, 2015. 
[38] M. M. Câmara, R. M. Soares, T. Feital et al., "On-line identification of fermentation processes for ethanol production," Bioprocess and Biosystems Engineering, vol. 40, no. 7, pp. 989-1006, 2017.

[39] C. T. Goudar, K. B. Konstantinov, and J. M. Piret, "Robust parameter estimation during logistic modeling of batch and fed-batch culture kinetics," Biotechnology Progress, vol. 25, no. 3, pp. 801-806, 2009.

[40] T. Van Daele, K. V. Gernaey, R. H. Ringborg et al., “Application of iterative robust model-based optimal experimental design for the calibration of biocatalytic models," Biotechnology Progress, vol. 33, no. 5, pp. 1278-1293, 2017.

[41] L. G. Encarnación-Gómez, A. S. Bommarius, and R. W. Rousseau, "Crystallization kinetics of ampicillin using online monitoring tools and robust parameter estimation," Industrial \& Engineering Chemistry Research, vol. 55, no. 7, pp. 2153-2162, 2016.

[42] C. Wang, Q. Duan, C. H. Tong, Z. Di, and W. Gong, "A GUI platform for uncertainty quantification of complex dynamical models," Environmental Modelling \& Software, vol. 76, pp. 1-12, 2016.

[43] M. N. Pantano, M. C. Fernández, L. Rodriguez, and G. Scaglia, "Optimización dinámica basada en Fourier. Aplicación al proceso de producción de Biodiesel," Revista Iberoamericana de Automática e Informática industrial, vol. 33, 2020.

[44] M. N. Pantano, M. C. Fernández, O. A. Ortiz, G. J. E. Scaglia, and J. R. Vega, "A Fourier-based control vector parameterization for the optimization of nonlinear dynamic processes with a finite terminal time," Computers \& Chemical Engineering, vol. 134, Article ID 106721, 2020.

[45] C. Fernández, N. Pantano, F. Rossomando, A. Amicarelli, and G. Scaglia, "Fermentation monitoring by Bayesian states estimators. Application to red wines elaboration," Control Engineering Practice, vol. 103, Article ID 104608, 2020.

[46] S. Valentinotti, B. Srinivasan, U. Holmberg et al., "Optimal operation of fed-batch fermentations via adaptive control of overflow metabolite," Control Engineering Practice, vol. 11, no. 6, pp. 665-674, 2003.

[47] O. L. Q. Montoya, A. A. Amicarelli, G. Scaglia, and F. di Sciascio, "Control based on numerical methods and recursive Bayesian estimation in a continuous alcoholic fermentation process," BioResources, vol. 4, pp. 1372-1395, 2009.

[48] M. C. Fernández, M. N. Pantano, L. Rodriguez, and G. Scaglia, "“State estimation and nonlinear tracking control simulation approach," Application to a Bioethanol Production System.," Bioprocess and Biosystems Engineering, In Press, 2020.

[49] U. Imtiaz, A. Assadzadeh, S. S. Jamuar, and J. N. Sahu, "Bioreactor temperature profile controller using inverse neural network (INN) for production of ethanol," Journal of Process Control, vol. 23, no. 5, pp. 731-742, 2013.

[50] M. C. Fernández, G. J. E. Scaglia, R. A. F. Machado, M. N. Pantano, and O. A. Ortiz, "Nonlinear multivariable tracking control: application to an ethanol process," International Journal of Automation and Control, vol. 13, no. 4, pp. 440-468, 2019.

[51] M. N. Pantano, M. a. C. Fernández, M. E. Serrano, O. A. Ortiz, and G. J. Scaglia, "Tracking control of optimal profiles in a nonlinear fed-batch bioprocess under parametric uncertainty and process disturbances," Industrial \& Engineering Chemistry Research, vol. 57, pp. 11130-11140, 2018.

[52] M. C. Fernández, M. Nadia Pantano, F. G. Rossomando, O. Alberto Ortiz, and G. J. Scaglia, "STATE estimation and trajectory tracking control for A nonlinear and multivariable bioethanol production system," Brazilian Journal of Chemical Engineering, vol. 36, pp. 421-437, 2019.

[53] D. V. Griffiths and I. M. Smith, Numerical Methods for Engineers, CRC Press, Boca Raton, FL, USA, 2006.

[54] G. Strang, "Linear algebra and its applications," Thomson, Brooks/Cole, Belmont, CA, USA, ISBN 0-030-10567-62006.

[55] R. Tempo and H. Ishii, "Monte Carlo and las vegas randomized algorithms for systems and control," European Journal of Control, vol. 13, no. 2-3, pp. 189-203, 2007.

[56] M. C. F. Puchol, M. N. Pantano, S. Godoy, E. Serrano, and G. Scaglia, "Optimización de Parámetros utilizando los métodos de Monte carlo y algoritmos evolutivos," Aplicación a un Controlador de Seguimiento de Trayectoria en Sistemas no Lineales," Revista Iberoamericana de Automática e Informática industrial, vol. 16, 2018.

[57] G. Scaglia, A. Rosales, L. Quintero, V. Mut, and R. Agarwal, "A linear-interpolation-based controller design for trajectory tracking of mobile robots," Control Engineering Practice, vol. 18, no. 3, pp. 318-329, 2010.

[58] E. Durand-Cartagena and J. A. Jaramillo, "Pointwise Lipschitz functions on metric spaces," Journal of Mathematical Analysis and Applications, vol. 363, no. 2, pp. 525-548, 2010.

[59] H. Michalska and D. Q. Mayne, "Robust receding horizon control of constrained nonlinear systems," IEEE Transactions on Automatic Control, vol. 38, no. 11, pp. 1623-1633, 1993.

[60] D. Q. Mayne, J. B. Rawlings, C. V. Rao, and P. O. M. Scokaert, "Constrained model predictive control: stability and optimality," Automatica, vol. 36, no. 6, pp. 789-814, 2000.

[61] F. B. Hildebrand, Introduction to Numerical Analysis: Courier Corporation, Courier Corporation, Chelmsford, MA, USA, 1987.

[62] Y. Mohammadi, A. S. Pakdel, M. R. Saeb, and K. Boodhoo, "Monte Carlo simulation of free radical polymerization of styrene in a spinning disc reactor," Chemical Engineering Journal, vol. 247, pp. 231-240, 2014.

[63] L. P. de Oliveira, J. J. Verstraete, and M. Kolb, “A Monte Carlo modeling methodology for the simulation of hydrotreating processes," Chemical Engineering Journal, vol. 207, pp. 94102, 2012.

[64] F. A. Cheein and G. Scaglia, "Trajectory tracking controller design for unmanned vehicles: a new methodology," Journal of Field Robotics, vol. 31, no. 6, pp. 861-887, 2014.

[65] M. C. Fernández, M. N. Pantano, E. Serrano, and G. Scaglia, "Multivariable tracking control of a bioethanol process under uncertainties," Mathematical Problems in Engineering, vol. 2020, Article ID 8263690, 16 pages, 2020.

[66] K. Y. Rani and V. R. Rao, "Control of fermenters-a review," Bioprocess Engineering, vol. 21, pp. 77-88, 1999.

[67] H. Wang, C. Wang, Y. Wang, X. Gao, and C. Yu, "Bayesian forecasting and uncertainty quantifying of stream flows using Metropolis-Hastings Markov chain Monte Carlo algorithm," Journal of Hydrology, vol. 549, pp. 476-483, 2017.

[68] A. Noruzi, T. Banki, O. Abedinia, and N. Ghadimi, "A new method for probabilistic assessments in power systems, combining Monte Carlo and stochastic-algebraic methods," Complexity, vol. 21, no. 2, pp. 100-110, 2015.

[69] Y. Liu, E. Jimenez, M. Y. Hussaini, G. Ökten, and S. Goodrick, "Parametric uncertainty quantification in the Rothermel model with randomised quasi-Monte Carlo methods," International Journal of Wildland Fire, vol. 24, no. 3, pp. 307316, 2015.

[70] H. Hao, K. Zhang, S. X. Ding, Z. Chen, and Y. Lei, “A datadriven multiplicative fault diagnosis approach for automation 
processes," ISA Transactions, vol. 53, no. 5, pp. 1436-1445, 2014.

[71] C. D. Karlgaard and H. Shen, "Robust state estimation using desensitized Divided Difference Filter," ISA Transactions, vol. 52, no. 5, pp. 629-637, 2013.

[72] K. Michail, A. C. Zolotas, and R. M. Goodall, "Optimised sensor selection for control and fault tolerance of electromagnetic suspension systems: a robust loop shaping approach," ISA Transactions, vol. 53, no. 1, pp. 97-109, 2014.

[73] D. Dochain, Automatic Control of Bioprocesses, John Wiley \& Sons, Hoboken, NJ, USA, 2013.

[74] A. Rincón, D. Piarpuzán, and F. Angulo, “A new adaptive controller for bio-reactors with unknown kinetics and biomass concentration: guarantees for the boundedness and convergence properties," Mathematics and Computers in Simulation, vol. 112, pp. 1-13, 2015.

[75] C. Bartolomeo and G. Mose, "Type-2 fuzzy control of a bioreactor," in Proceedings of the IEEE International Conference on Intelligent Computing and Intelligent Systems, 2009, pp. 700-704, Shanghai, China, December 2009.

[76] F. Mairet and J.-L. Gouze, "Hybrid control of a bioreactor with quantized measurements," IEEE Transactions on Automatic Control, vol. 61, pp. 1385-1390, 2015.

[77] G. Lara-Cisneros, R. Femat, and D. Dochain, "An extremum seeking approach via variable-structure control for fed-batch bioreactors with uncertain growth rate," Journal of Process Control, vol. 24, no. 5, pp. 663-671, 2014.

[78] C. Cimander and C.-F. Mandenius, "Bioprocess control from a multivariate process trajectory," Bioprocess and Biosystems Engineering, vol. 26, no. 6, pp. 401-411, 2004.

[79] M. Elenchezhiyan and J. Prakash, "State estimation of stochastic non-linear hybrid dynamic system using an interacting multiple model algorithm," ISA Transactions, vol. 58, pp. 520-532, 2015. 